\title{
NECK CIRCUMFERENCE AS AN INDICATOR OF OBESITY IN YOUNG ADULTS
}

\author{
VINODHINI VM ${ }^{1 *}$, VINOTHKUMAR GANESAN ${ }^{2}$
}

${ }^{1}$ Department of Biochemistry, SRM Medical College Hospital and Research Centre, Kattankulathur, Chennai, Tamil Nadu, India. ${ }^{2}$ Department of Medical Research, SRM Medical College Hospital and Research Centre, Kattankulathur, Chennai, Tamil Nadu, India. Email: vinodhini239@gmail.com

Received: 26 September 2017, Revised and Accepted: 14 December 2017

ABSTRACT

Objective: Neck circumference (NC) is considered to be an indicator of upper-body subcutaneous adipose tissue distribution. An upper body distribution of fat, especially with increased visceral adipose tissue, is considered to be predictive of cardiometabolic outcomes. Therefore, in this study, we have studied the relationship between NC and the conventional marker of obesity, namely, body mass index (BMI) and also the triglyceride levels in a group of young adults.

Methods: There were 60 participants in this study in the age group of 18-42 years of both genders with no known major medical conditions (viz., diabetes, coronary artery disease, hypertension, thyroid diseases, or malignancy) NC was measured at mid-neck height. The analysis of serum triglycerides was carried out after an overnight fast using Beckman Coulter autoanalyzer.

Results: A significantly positive correlation was found between NC and BMI ( $\mathrm{r}=0.8154, \mathrm{p}<0.0001)$. A positive correlation was found between NC and triglyceride levels ( $r=0.0316, \mathrm{p}=0.9934)$.

Measurement of NC may be more useful in morbidly obese people, bedridden patients, and pregnant women. NC is found to have a positive correlation with insulin resistance and various components of the metabolic syndrome.

Conclusion: NC can be considered as a simple, useful, and reliable tool to identify overweight and obesity. This can be used as an alternative method to assess the fat distribution in health-care centers and also in population studies

Keywords: Obesity, Body mass index, Neck circumference.

(C) 2018 The Authors. Published by Innovare Academic Sciences Pvt Ltd. This is an open access article under the CC BY license (http://creativecommons. org/licenses/by/4. 0/) DOI: http://dx.doi.org/10.22159/ajpcr.2018.v11i3.22773

\section{INTRODUCTION}

Obesity is one of the most important risk factors for various cardiometabolic diseases namely diabetes, hypertension, dyslipidemia, and coronary heart disease [1-3]. With the increasing proportions of the global prevalence of obesity, it becomes important to identify measures of obesity in a quick and accurate manner. An early and quick assessment of obese individuals may help to improve the stratification of disease risk and also help in planning prevention and intervention strategies in an effective manner [4].

Body mass index (BMI) is one of the most widely used tools to assess the weight status in adults and children [5] despite the advantages of ease of measurement and interpretation, BMI is associated with significant limitations as not representing the body fat distribution [6,7]. An upper body distribution of fat, especially with increased visceral adipose tissue (VAT), is considered to be predictive of cardiometabolic outcomes [8-10].

Computed tomography and MRI and dual-energy X-ray absorptiometry are considered to be the gold standard methods for measuring visceral fat [11]. However, these techniques are expensive and not feasible for large epidemiological studies or routine use [12]

Neck circumference (NC) is a marker of upper body subcutaneous adipose tissue distribution and is considered to be a reliable index for obesity [13].

NC measurement is a simple and time-saving screening measure that can be used to identify overweight and obese individuals [14]. Type II diabetes mellitus is associated with and obesity regardless of age, race, and gender [15]. Regional adipose tissue handles and stores excess dietary energy, which may result in significant cardiometabolic implications. Therefore, the distribution of this regional adipose tissue or ectopic fat may be an important vascular risk in addition to overall obesity. Among the various ectopic fat deposition, the VAT is regarded as the most pathogenic fat depot, beyond the standard obesity indices [16]. Visceral adiposity predicts hepatic insulin resistance in patients with diabetes mellitus [17]

Waist circumference (WC) has long been used as a measure of central adiposity, and many studies have reported the strong association of WC with cardiovascular and metabolic risk $[18,19]$. However, it includes both visceral and subcutaneous fat [20]. Enzyme analysis may also be useful to assess the visceral fat deposition in the body. Serum gammaglutamyltransferase levels have been reported to be a simple and reliable marker of obesity [21]

An independent association of NC with visceral adiposity and BMI has been demonstrated by the Framingham heart study [22]. NC has shown to have a positive correlation with insulin resistance and various components of the metabolic syndrome $[10,23]$. Since anthropometric assessment is easy and practical, the $\mathrm{NC}$ can be used as an early predictor for excess body fat in children also [24]. Unlike the WC, measurement of NC does not show variations throughout the day.

NC as an indicator of upper-body subcutaneous adipose tissue distribution has been investigated as a screening tool to identify overweight individuals due to its ease in measurement and in being inexpensive and noninvasive. Therefore, in this study, we have studied the relationship between NC and the conventional marker of obesity, 
Table 1: Correlation between NC and BMI

\begin{tabular}{|c|c|c|c|}
\hline Parameters & $\begin{array}{l}\text { Mean } \pm S D \\
\text { value }\end{array}$ & Regression value & p value \\
\hline $\begin{array}{l}\text { Neck } \\
\text { circumference }(\mathrm{cm}) \\
\text { BMI } \\
\left(\mathrm{kg} / \mathrm{mt}^{2}\right)\end{array}$ & $\begin{array}{l}40.5 \pm 3 \\
24.2 \pm 5.1\end{array}$ & 0.8154 & $<0.0001$ \\
\hline
\end{tabular}

Table 2: Correlation between NC and triglycerides

\begin{tabular}{llll}
\hline Parameters & $\begin{array}{l}\text { Mean } \pm \text { SD } \\
\text { value }\end{array}$ & Regression value & p value \\
\hline NC $(\mathrm{cm})$ & $40.5 \pm 3$ & 0.0316 & $<0.9934$ \\
Triglycerides $(\mathrm{mg} / \mathrm{dl})$ & $179.8 \pm 84.6$ & & \\
\hline
\end{tabular}

NC: Neck circumference, SD: Standard deviation

namely, BMI and also the triglyceride levels in a group of young adults.

\section{METHODS}

The study was conducted after obtaining approval from the Institutional Ethics Committee (661/IEC/2014). There were 60 participants in the study in the age group of 18-42 years of both genders with no known major medical conditions (viz., diabetes, coronary artery disease, hypertension, thyroid diseases, or malignant disease) all the subjects were recruited from the master health checkup program of our medical college hospital. Those who were on lipid-lowering drugs were not recruited for the present study.

Informed consent was obtained from all of them. All measurements were made by one investigator using standard techniques as follows: weight by standardized digital scales to within $100 \mathrm{~g}$, without heavy clothing; height by standardized stadiometer to within $0.5 \mathrm{~cm}$, while barefoot. NC was measured at mid-neck height, between mid-cervical spine and mid-anterior neck, to within $1 \mathrm{~mm}$, with plastic measuring tapes. In men with a laryngeal prominence (Adam's apple), NC was measured just below the prominence. All the measurements were taken with the participants in upright posture and facing the investigator, with their shoulders relaxed.

After an overnight fast, $3 \mathrm{ml}$ of venous blood sample was collected from the participants using a vacutainer. Analysis of triglycerides was carried out using Beckman Coulter automated clinical chemistry analyzer by means of standard biochemical procedures in the clinical biochemistry laboratory at our medical college hospital.

\section{RESULTS}

We examined the relationship between NC and BMI. The linear regression analysis was carried out on a scatter plot of NC and BMI. The Pearson's correlation coefficient was determined. A significantly positive correlation was found between NC and BMI ( $\mathrm{r}=0.8154$, $\mathrm{p}<0.0001)$.

We examined the relationship between NC and triglycerides levels. The linear regression analysis was carried out on a scatter plot of NC and triglycerides levels. The Pearson's correlation coefficient was determined. A positive correlation was found between $\mathrm{NC}$ and Triglycerides levels $(\mathrm{r}=0.0316, \mathrm{p}=0.9934)$.

\section{DISCUSSION}

Obesity is a known risk factor for the development of various cardiovascular and metabolic disturbances. Obesity is usually assessed by $\mathrm{BMI}, \mathrm{WC}$, and waist/hip ratio. An independent association of NC with visceral adiposity and BMI has been demonstrated by the Framingham heart study [20]. We have observed a positive correlation between NC and BMI in our study Table 1. An upper body distribution of fat, especially with increased VAT, is considered predictive of cardiometabolic conditions [8-10].

Several studies have shown a significant positive association of NC with BMI and WC $[23,25,26]$. Due to cultural factors, the measurement of hip or WC may be difficult in certain situations [26]. Measurement of NC may be more useful in morbidly obese people, bedridden patients, and pregnant women [27].

A positive association has been reported between NC and serum triglyceride levels in our study Table 2 . The upper body subcutaneous fat depots are one of the main determinants of the systemic-free fatty acid concentrations [28]. The free fatty acid release from upper body subcutaneous fat has been reported to be larger than that from lowerbody subcutaneous fat. The measurement of upper body subcutaneous adipose tissue depots assumes greater relevance in this regard [23].

The association observed between neck fat, and components of metabolic syndrome may be attributed to an excess release of free fatty acids into plasma from the upper body subcutaneous fat [10]. NC is found to have a positive correlation with insulin resistance and the various biochemical components of the metabolic syndrome.

The NC was found to correlate with the various components of the metabolic syndrome, namely, high triglycerides and fasting glucose levels, low high-density lipoprotein cholesterol levels, and insulin resistance index in a large population-based study $[10,22]$.

The Korean Genome and Epidemiology Study involving 10038 subjects reported a positive correlation of NC with serum triglyceride levels [29]. The limitations of our study are that the participants were chosen from a single center and only single estimations of the anthropometric measurements and blood estimations were carried out.

In conclusion, $\mathrm{NC}$ can be considered as a simple, useful, and reliable tool to identify overweight and obesity. This can be used as an alternative method to assess the fat distribution in health-care centers and also in population studies.

\section{ACKNOWLEDGMENT}

The authors thank the valuable study subjects.

\section{AUTHORS CONTRIBUTION}

All the authors have contributed equally.

\section{CONFLICTS INTEREST}

All authors have no conflicts of interest to declare.

\section{REFERENCES}

1. Klein S, Allison DB, Heymsfield SB, Kelley DE, Leibel RL, Nonas C, et al. Waist circumference and cardiometabolic risk: A consensus statement from shaping America's health: Association for weight management and obesity prevention; NAASO, the obesity society; the American society for nutrition; and the American diabetes association. Am J Clin Nutr 2007;85:1197-202.

2. Nakamura Y, Turin TC, Kita Y, Tamaki S, Tsujita Y, Kadowaki T, et al. Associations of obesity measures with metabolic risk factors in a community-based population in Japan. Circ J 2007;71:776-81

3. Palacios C, Pérez CM, Guzmán M, Ortiz AP, Ayala A, Suárez E, et al. Association between adiposity indices and cardiometabolic risk factors among adults living in Puerto Rico. Public Health Nutr 2011;14:1714 23 .

4. Papandreou D, Noor ZT, Rashed M, Jaberi HA. Association of neck circumference with obesity in female college students. Open Access Maced J Med Sci 2015;3:578-81.

5. Rothman KJ. BMI-related errors in the measurement of obesity. Int J Obes (Lond) 2008;32 Suppl 3:S56-9.

6. Obesity: Preventing and managing the global epidemic. Report of a WHO consultation. World Health Organ Tech Rep Ser 2000;894:i-xii, 1-253. 
7. Walton C, Lees B, Crook D, Worthington M, Godsland IF, Stevenson JC, et al. Body fat distribution, rather than overall adiposity, influences serum lipids and lipoproteins in healthy men independently of age. Am J Med 1995;99:459-64.

8. Kissebah AH, Peiris AN. Biology of regional body fat distribution: Relationship to non-insulin-dependent diabetes mellitus. Diabetes Metab Rev 1989;5:83-109.

9. Levine JA, Ray A, Jensen MD. Relation between chubby cheeks and visceral fat. N Engl J Med 1998;339:1946-7.

10. Preis SR, Massaro JM, Hoffmann U, D’Agostino RB Sr, Levy D, Robins SJ, et al. Neck circumference as a novel measure of cardiometabolic risk: The Framingham heart study. J Clin Endocrinol Metab 2010;95:3701-10.

11. Micklesfield LK, Goedecke JH, Punyanitya M, Wilson KE, Kelly TL. Dual-energy X-ray performs as well as clinical computed tomography for the measurement of visceral fat. Obesity (Silver Spring) 2012;20:1109-14.

12. Wells JC, Fewtrell MS. Measuring body composition. Arch Dis Child 2006;91:612-7.

13. Aswathappa J, Garg S, Kutty K, Shankar V. Neck circumference as an anthropometric measure of obesity in diabetics. N Am J Med Sci 2013;5:28-31.

14. Ben-Noun L, Sohar E, Laor A. Neck circumference as a simple screening measure for identifying overweight and obese patients. Obes Res 2001;9:470-7.

15. Arafat MO, Salam AI, Arafat OS. The association of Type 2 diabetes with obesity and other factors: In multinational community. Int J Pharm Pharm Sci 2014;6:257-60.

16. 1Fox CS, Massaro JM, Hoffmann U, Pou KM, Maurovich-Horvat P, Liu CY, et al. Abdominal visceral and subcutaneous adipose tissue compartments: Association with metabolic risk factors in the Framingham heart study. Circulation 2007;116:39-48.

17. Pathak KY, Mohanan A, Acharya S, Mandavia D, Jadhav HR. Exploring visceral adiposity index as a predictor of visceral adiposity dysfunction and evaluating its performance in predicting hepatic insulin resistance in Indian Type 2 diabetics. Int J Pharm Pharm Sci 2016;8:297-301.

18. Seidell JC, Pérusse L, Després JP, Bouchard C. Waist and hip circumferences have independent and opposite effects on cardiovascular disease risk factors: The Quebec family study. Am J Clin Nutr
$2001 ; 74: 315-21$

19. Zhu S, Wang Z, Heshka S, Heo M, Faith MS, Heymsfield SB, et al. Waist circumference and obesity-associated risk factors among whites in the third national health and nutrition examination survey: Clinical action thresholds. Am J Clin Nutr 2002;76:743-9.

20. Weits T, van der Beek EJ, Wedel M, Ter Haar Romeny BM. Computed tomography measurement of abdominal fat deposition in relation to anthropometry. Int J Obes 1988;12:217-25.

21. Vinodhini VM, Sudhan KB. Gamma-glutamyl transferase as an indicator of obesity: A cross-sectional study. Asian J Pharm Clin Res 2016;9:240-2

22. Saka M, Türker P, Ercan A, Kiziltan G, Baş M. Is neck circumference measurement an indicator for abdominal obesity? A pilot study on Turkish adults. Afr Health Sci 2014;14:570-5

23. Stabe C, Vasques AC, Lima MM, Tambascia MA, Pareja JC, YamanakaA, et al. Neck circumference as a simple tool for identifying the metabolic syndrome and insulin resistance: Results from the Brazilian metabolic syndrome study. Clin Endocrinol (Oxf) 2013;78:874-81.

24. Atef A, Ibrahim A, Hassan NE, Elmasry SA, Elashry GI. Neck circumference as a novel screening method for estimating fat distribution and metabolic complications in obese children. Egypt Pediatr Assoc Gaz 2015;63:91-7.

25. Hingorjo MR, Qureshi MA, Mehdi A. Neck circumference as a useful marker of obesity: A comparison with body mass index and waist circumference. J Pak Med Assoc 2012;62:36-40.

26. Kumar S, Gupta A, Jain S. Neck circumference as a predictor of obesity and overweight in rural central India. Int J Med Public Health 2012;2:62-6.

27. Joshipura K, Muñoz-Torres F, Vergara J, Palacios C, Pérez CM. Neck circumference may be a better alternative to standard anthropometric measures. J Diabetes Res 2016;2016:6058916.

28. Koutsari C, Jensen MD. Thematic review series: Patient-oriented research. Free fatty acid metabolism in human obesity. J Lipid Res 2006;47:1643-50.

29. Cho NH, Oh TJ, Kim KM, Choi SH, Lee JH, Park KS, et al. Neck circumference and incidence of diabetes mellitus over 10 years in the Korean genome and epidemiology study (KoGES). Sci Rep 2015;5:18565. 